\title{
Treatment of Adrenal Metastases with Conventional or Hypofractionated Image-guided Radiation Therapy - Patterns and Outcomes
}

\author{
DANIEL BUERGY ${ }^{1}$, LEONIE RABE $^{1}$, KERSTIN SIEBENLIST $^{1}$, FLORIAN STIELER ${ }^{1}$, JENS FLECKENSTEIN $^{1}$, \\ FRANK A. GIORDANO ${ }^{1,2}$, FREDERIK WENZ ${ }^{1}$ and JUDIT BODA-HEGGEMANN ${ }^{1}$ \\ ${ }^{1}$ Department of Radiation Oncology, Universitätsmedizin Mannheim, \\ Medical Faculty Mannheim, Heidelberg University, Mannheim, Germany; \\ ${ }^{2}$ Translational Radiation Oncology, Department of Radiation Oncology, \\ Universitätsmedizin Mannheim, Medical Faculty Mannheim, Heidelberg University, Mannheim, Germany
}

\begin{abstract}
Background/Aim: Metastases involving the adrenal glands can be treated surgically or with radiation therapy. Retrospective studies indicate that radiotherapy for this indication is safe, well-tolerated and associated with symptom palliation and good local control. We conducted this analysis to report on patterns and outcomes of patients with adrenal metastases treated with hypo- or conventionally fractionated image-guided radiotherapy. Patients and Methods: Patients with adrenal metastases from solid tumors treated at our department between 01/2010-12/2017 were reviewed. A total of 22 lesions were treated in 18 patients with a median dose of $35 \mathrm{~Gy}$ (20-60 Gy) in a median number of 7 (4-25) fractions. Results: No grade $\geq 3$ toxicity occurred. Median overall survival was 11.9 months. Five local failures occurred (22.7\%). Lesion sizes or radiation dose were not correlated with local control. Patients treated for oligometastatic and oligoprogressive disease had a median overall survival of 33 and 6.5 months, respectively (palliative/polymetastatic: 1.6 months). Symptoms improved in all patients treated for clinically apparent lesions. Conclusion: Stereotactic radiotherapy of adrenal metastases was safe and effective in patients with oligometastases or oligoprogression. In palliative patients, short-course radiotherapy complemented with supportive care should be preferred.
\end{abstract}

Correspondence to: Daniel Buergy, Department of Radiation Oncology; Universitätsmedizin Mannheim, Medical Faculty Mannheim, Heidelberg University, Mannheim, Germany. Tel: +49 621836020 , e-mail: daniel.buergy@umm.de

Key Words: Adrenal metastases, radiation therapy, SBRT, oligometastases, oligoprogression.
Metastases involving the adrenal gland can be observed during the natural history of disease in different solid malignancies, including renal cell carcinoma (RCC), nonsmall cell lung cancer (NSCLC), colorectal cancer (CRC) and prostate carcinoma, among others (1). Adrenalectomy in selected patients is an effective local treatment with a local control (LC) of $84 \%$ and a two-year overall survival (OS) of $46 \%$ in a recent meta-analysis (2). Peri-operative deaths occurred in $0.75 \%$ of patients; however, the incidence of other complications was not consistently reported in the analyzed studies (2). Historically, conventional radiotherapy has been performed mostly for symptomatic lesions with pain improvements in $75 \%$ of patients (3).

Since the description of an oligometastatic state by Hellman and Weichselbaum in 1995, more and more patients received ablative local therapy to metastatic or recurrent malignancies of the adrenal gland $(2,4)$. Most authors consider oligometastatic disease as a state of limited metastases, typically 3-5 sites, which can be cured in some patients by aggressive local therapy (5). The term oligoprogression as a distinct state of disease has been proposed to describe metachronous oligometastases (6). Other authors defined oligoprogression as a limited number of progressive lesions in a patient with otherwise stable disease, irrespective of the total number of lesions (7). Highly conformal radiotherapy techniques such as intensitymodulated radiotherapy (IMRT) or stereotactic body radiotherapy (SBRT) to adrenal lesions showed favorable safety profiles in multiple studies reported on patients with oligometastatic or symptomatic lesions (8). A systematic review found no grade 3 or higher toxicities in a wide variety of dose- and fractionation regimens. LC rates ranged from 44 to $100 \%$ at one, and from $27-100 \%$ at two years (8). Rudra and coworkers analyzed a patient cohort consisting only of patients with oligometastatic disease. The median OS 
in this favorable patient population was 17.3 months (9). In patients with solitary lesions, analyzed by Holy et al., OS was 23 months and progression-free survival (PFS) was 12 months, similar to surgical series $(8,10,11)$.

In this study, we report on a mono-institutional series of all patients treated with radiotherapy for adrenal metastases at our Institution during the last eight years for oligometastatic, oligoprogressive, or symptomatic disease.

\section{Patients and Methods}

Patients. The study was approved by the ethics committee of Heidelberg University, Medical Faculty Mannheim (2018-804RMA). In the present study, oligoprogressive disease was defined as a limited number of progressive lesions $(n \leq 3)$ in a patient with otherwise stable disease, irrespective of the total number of metastases (7). Oligometastatic disease was defined as a maximum of 5 metastases with controlled or potentially controllable primary tumor. All health records from January 2010 to December 2017 were screened for patients with adrenal metastases.

Toxicity analysis. All irradiated patients were included in the analysis of acute toxicity. Patients with at least one follow-up of 90 days or longer were included in the late-toxicity analysis. Grading of adverse events was done using the Common Terminology Criteria for Adverse Events (CTCAE), Version 4.0 (12).

Efficacy analysis. All patients were included in the OS, PFS, and LC analysis. We used the interval from the beginning of radiotherapy to the last follow-up visit or date of death for the survival analysis. Time to local failure was calculated using the last imaging of the irradiated lesion as the end date. Imaging of lesions and follow-up visits may differ in some patients with long followup because imaging was not mandatory in each follow-up visit. For the LC analysis, the exact date of each irradiated lesion was used as a start date for follow-up (to achieve a side-specific LC outcome result).

Radiotherapy. Treatment planning was based on computed tomography in all cases. All patients were treated with volumetric modulated arc therapy (VMAT). Computer-controlled Deepinspiration breath-hold (DIBH) was applied with ABC (Elekta AB, Stockholm, Sweden), whenever patients were sufficiently able to follow the commands and when sparing of normal tissues was better compared to plans delivered in free-breathing techniques $(n=18)(13)$. Daily image guidance was performed with breath-hold cone-beam CT (14). In 18 cases the dose was prescribed uniformly to the PTV and normalized to the median. Non-uniform dose distribution as described previously (15) was done in four patients. A typical dose distribution is shown in Figure 1. Details on irradiated volumes, doses, fractionations, biologically effective doses (BED), and equivalent dose in 2 Gy fractions (EQD-2) are shown in Tables I and II.

Statistics. All statistical calculations were performed using SPSS (V 15.0), or "R", a language and environment for statistical computing that is available for free online (https://www.r-project.org/) (16). Spearman's nonparametric correlation coefficient was computed to identify correlations between nonparametric variables. Differences of nonparametric variables were computed using the two-sample
Table I. Individual patient data, dose to kidney and intestine.

\begin{tabular}{|c|c|c|c|c|}
\hline Lesion & $\begin{array}{l}\text { Prescribed } \\
\text { nominal } \\
\text { dose } \\
\text { (fractions) }\end{array}$ & $\begin{array}{l}\text { Mean dose } \\
\text { to ipsilateral } \\
\text { kidney } \\
\text { (Gy) }\end{array}$ & $\begin{array}{c}\text { Mean dose } \\
\text { to contralateral } \\
\text { kidney } \\
\text { (Gy) }\end{array}$ & $\begin{array}{c}\text { Maximum } \\
\text { point } \\
\text { dose small } \\
\text { intestine }(\mathrm{Gy})\end{array}$ \\
\hline NSCLC-1 & 30 Gy (10) & 7.7 & 3.6 & 31.1 \\
\hline NSCLC-2 & 60 Gy (12) & 1.1 & 1.7 & $60.05^{\S}$ \\
\hline NSCLC-3 & 39 Gy (13) & $27.7^{ \pm}$ & 7.7 & 37.7 \\
\hline NSCLC-4 & 35 Gy (5) & 5.9 & 0.8 & 18.5 \\
\hline NSCLC-5 & 25 Gy (5) & 5.8 & 0.8 & 14 \\
\hline NSCLC-6 & 39 Gy (13) & 7.3 & 0.7 & 14.5 \\
\hline NSCLC-7 & 39 Gy (13) & 4.1 & 2.4 & 12 \\
\hline SCLC-1 & $20 \mathrm{~Gy}(4)$ & $4.7 * 1$ & $1.3 * 1$ & 20.5 \\
\hline SCLC-2 & 20 Gy (4) & $4.25 * 1$ & $0.4^{* 1}$ & 20.7 \\
\hline SCLC-3 & 39 Gy (13) & 5.7 & 2.2 & 35.8 \\
\hline Sarcoma-1 & 35 Gy (5) & 8.1 & 2.6 & 33.2 \\
\hline Sarcoma-2 & 45 Gy (25) & $15.2^{ \pm}$ & 2.4 & 46.9 \\
\hline Sarcoma-3 & 39 Gy (13) & $17.4^{ \pm}$ & 4.9 & 38.4 \\
\hline Melanoma-1 & 60 Gy (5) & $7.9 * 2$ & $1.3 * 2$ & 38.41 \\
\hline Melanoma-2 & 35 Gy (5) & $4.3 * 2$ & $0.8 * 2$ & 36.2 \\
\hline Rectal-1 & 20 Gy (5) & 4.6 & 1.2 & 5.8 \\
\hline Rectal-2 & 35 Gy (7) & 7.5 & 2.2 & 34.1 \\
\hline Prostate-1 & 25 Gy (5) & $1.8 * 3$ & $0.3 * 3$ & 12.2 \\
\hline Prostate-2 & 36 Gy (12) & $5.1 * 3$ & $1.5 * 3$ & 37.8 \\
\hline Prostate-3 & 35 Gy (7) & $5.1 * 4$ & $0.4 * 4$ & 35.7 \\
\hline Prostate-4 & 35 Gy (7) & $4.9 * 4$ & $2.1 * 4$ & 9.4 \\
\hline HCC-1 & 60 Gy (12) & 11.1 & 2.2 & 28.4 \\
\hline
\end{tabular}

*1-4Indicates irradiation in one patient; therefore, doses to the ipsilateral kidney have to be added to the contralateral dose of the contralateral plan and vice versa. ${ }^{\S}$ Dose to $1 \mathrm{ccm}=43.568 \mathrm{~Gy} ; 2.5 \mathrm{ccm}=34.37 \mathrm{~Gy}$; $5 \mathrm{ccm}=28.91 \mathrm{~Gy} . \pm$ Renal function tests had been performed for the contralateral kidney before dose was applied. HCC: Hepatocellular carcinoma; NSCLC: non-small-cell lung cancer; SCLC small-cell lung cancer.

paired Wilcoxon test. Survival curves were calculated by using Kaplan-Meier analysis, and differences were tested by Mantel-Cox log-rank statistics.

\section{Results}

From January 2010 to December 2017, a total of 18 patients were treated for secondary adrenal cancers. In four patients, both sides were treated for 22 treated lesions in total (right: $\mathrm{n}=10$, left: $\mathrm{n}=12$ ). One patient received postoperative radiotherapy after surgical resection with macroscopic residual tumor (R2). Primary tumors were NSCLC in seven (adenocarcinoma, $\mathrm{n}=4$, squamous cell, $\mathrm{n}=2$, large-cell, $\mathrm{n}=1$ ), sarcomas in three (angiosarcoma, myxoid liposarcoma, and undifferentiated pleomorphic sarcoma, the latter postoperatively), prostate, rectal, and small-cell lung cancer (SCLC) in two cases each, one patient with hepatocellular carcinoma (HCC) and one patient with melanoma (see Table III for details). 
a

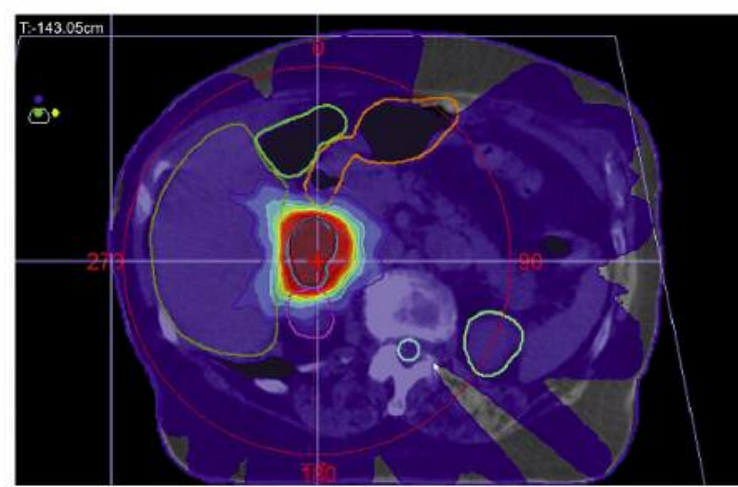

C
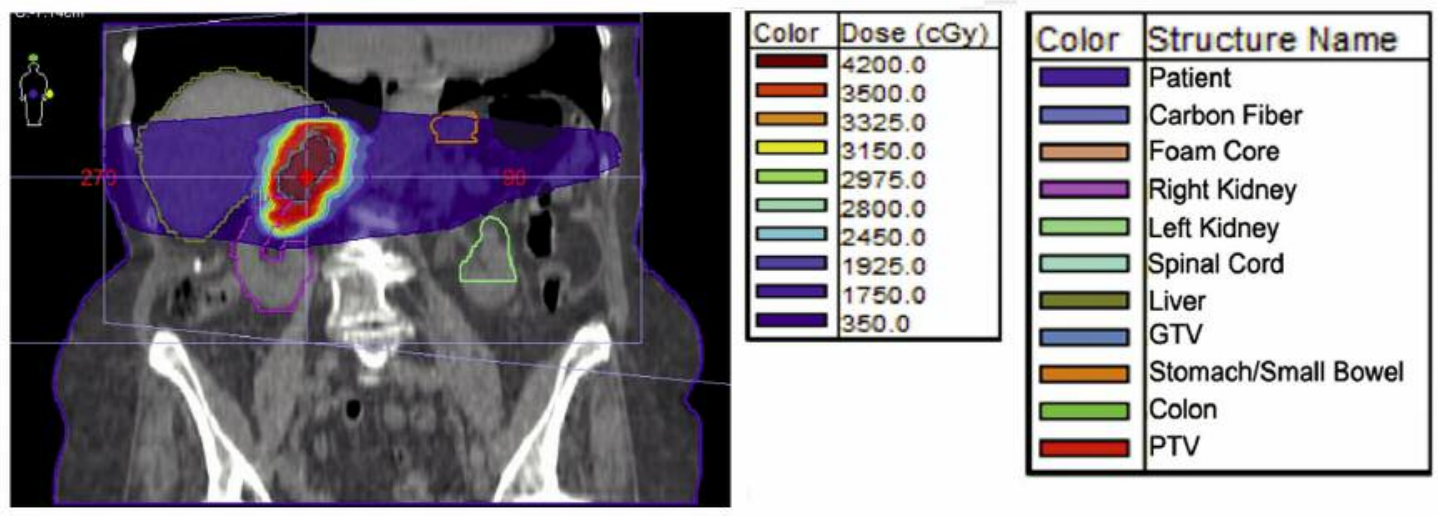

\section{d Dose-Volume Histogram}

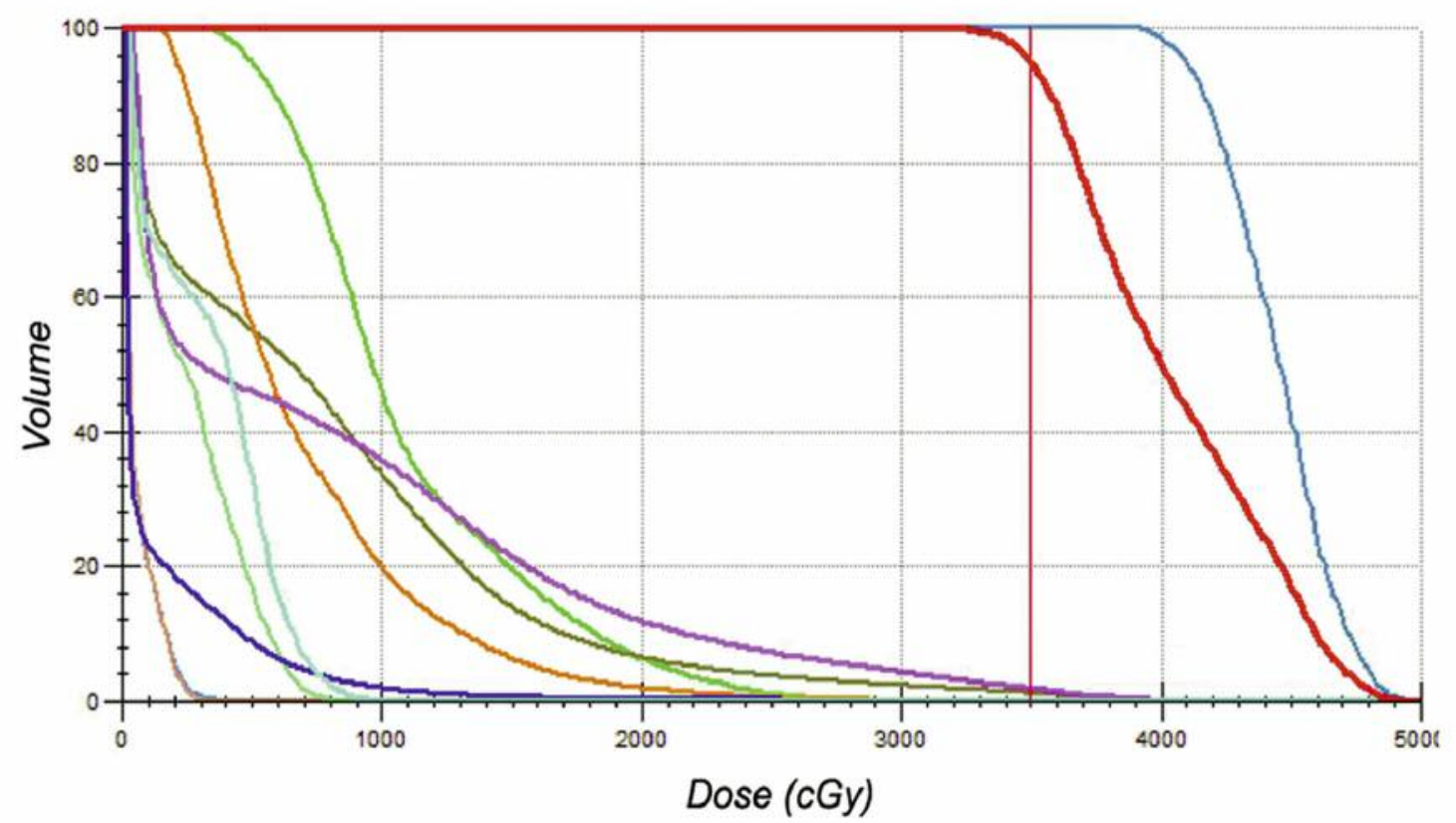

Figure 1. Dose distribution. Dose distribution of an inhomogeneous plan with a total dose of 35 Gy in seven fractions prescribed to the D95\%. The patient received a mean dose of $40.5 \mathrm{~Gy}$ to the PTV (range=30.8-50 Gy). Max point dose to the small bowel, the left, and the right kidney were $33.2 \mathrm{~Gy}, 8.6 \mathrm{~Gy}$, and $42.8 \mathrm{~Gy}$, respectively. 
Table II. Individual patient data, dose parameters and local control.

\begin{tabular}{|c|c|c|c|c|c|c|}
\hline Lesion & $\begin{array}{c}\text { Prescribed } \\
\text { dose } \\
\text { (fractions) }\end{array}$ & $\begin{array}{c}\text { PTV, BED } \\
\text { mean dose } \\
\text { (range) in Gy }\end{array}$ & $\begin{array}{l}\text { PTV, EQD-2 } \\
\text { mean dose } \\
\text { (range) in Gy }\end{array}$ & $\begin{array}{l}\text { GTV, BED } \\
\text { mean dose } \\
\text { (range) in Gy }\end{array}$ & $\begin{array}{l}\text { Volume of } \\
\text { GTV }(\mathrm{ccm})\end{array}$ & $\begin{array}{l}\text { Local } \\
\text { failure }\end{array}$ \\
\hline NSCLC-1 & $30 \mathrm{~Gy}(10)$ & $\begin{array}{c}38.7 \\
(23.9-44.6)\end{array}$ & $\begin{array}{c}32.2 \\
(19.9-37.1)\end{array}$ & $\begin{array}{c}39.4 \\
(36.9-42.9)\end{array}$ & 65.3 & Yes \\
\hline NSCLC-2 & $60 \mathrm{~Gy}(12)$ & $\begin{array}{c}89.8 \\
(62.6-99.7)\end{array}$ & $\begin{array}{c}74.9 \\
(56.7-80.9)\end{array}$ & $\begin{array}{c}89.8 \\
(85.8-99.4)\end{array}$ & 7.6 & No \\
\hline NSCLC-3 & 39 Gy (13) & $\begin{array}{c}50.1 \\
(29.3-54.3)\end{array}$ & $\begin{array}{c}41.7 \\
(26.6-44.6)\end{array}$ & $\begin{array}{c}50.7 \\
(45.6-54.2)\end{array}$ & 196.7 & No \\
\hline NSCLC-4 & 35 Gy (5) & $\begin{array}{c}59.2 \\
(47-65.1)\end{array}$ & $\begin{array}{c}49.3 \\
(41.8-52.8)\end{array}$ & $\begin{array}{c}59.4 \\
(55.8-64.2)\end{array}$ & 12.2 & No \\
\hline NSCLC-5 & 25 Gy (5) & $\begin{array}{c}37.2 \\
(28.8-39.2)\end{array}$ & $\begin{array}{c}31 \\
(25.5-32.2)\end{array}$ & $\begin{array}{c}37.6 \\
(35.2-39.3)\end{array}$ & 16.1 & No \\
\hline NSCLC-6 & 39 Gy (13) & $\begin{array}{c}50.3 \\
(41.4-53.1)\end{array}$ & $\begin{array}{c}41.9 \\
(35.7-43.8)\end{array}$ & $\begin{array}{c}50.4 \\
(48.5-52)\end{array}$ & 8 & No \\
\hline NSCLC-7 & 39 Gy (13) & $\begin{array}{c}50.1 \\
(40-53.7)\end{array}$ & $\begin{array}{c}41.7 \\
(34.7-44.2)\end{array}$ & $\begin{array}{c}51.1 \\
(47.9-53.5)\end{array}$ & 46.8 & - \\
\hline SCLC-1 & 20 Gy (4) & $\begin{array}{c}31.2 \\
(21-34.4)\end{array}$ & $\begin{array}{c}26 \\
(19.2-28)\end{array}$ & $\begin{array}{c}31.9 \\
(29-34.4)\end{array}$ & 56.5 & - \\
\hline SCLC-2 & 20 Gy (4) & $\begin{array}{c}31.3 \\
(21.9-34.5)\end{array}$ & $\begin{array}{c}26.1 \\
(19.8-28)\end{array}$ & $\begin{array}{c}32.3 \\
(29.1-34.2)\end{array}$ & 127.6 & - \\
\hline SCLC-3 & 39 Gy (13) & $\begin{array}{c}50.4 \\
(44.5-52.9)\end{array}$ & $\begin{array}{c}42 \\
(37.9-43.7)\end{array}$ & $\begin{array}{c}50.9 \\
(49.2-52.8)\end{array}$ & 52.1 & No \\
\hline Sarcoma-1 & 35 Gy (5) & $\begin{array}{c}73.2 \\
(49.7-100)\end{array}$ & $\begin{array}{c}61 \\
(46.4-75.4)\end{array}$ & $\begin{array}{c}83.9 \\
(69-100)\end{array}$ & 27.8 & No \\
\hline Sarcoma-2 & $45 \mathrm{~Gy}(25)$ & $\begin{array}{c}52.8 \\
(35.2-58.7)\end{array}$ & $\begin{array}{c}44 \\
(30.7-48.2)\end{array}$ & $\begin{array}{l}\text { Not Applicable } \\
\text { (Postoperative) }\end{array}$ & $\begin{array}{c}\text { Not } \\
\text { Applicable }\end{array}$ & No \\
\hline Sarcoma-3 & 39 Gy (13) & $\begin{array}{c}50.5 \\
(40.7-53.5)\end{array}$ & $\begin{array}{c}42.1 \\
(35.3-44.1)\end{array}$ & $\begin{array}{c}50.6 \\
(48.6-53.6)\end{array}$ & 261.5 & No \\
\hline Melanoma-1 & 60 Gy (5) & $\begin{array}{c}144.7 \\
(93.7-190.3)\end{array}$ & $\begin{array}{c}120.6 \\
(90.7-143.4)\end{array}$ & $\begin{array}{c}150.2 \\
(115.8-178.6)\end{array}$ & 25.2 & Yes \\
\hline Melanoma-2 & 35 Gy (5) & $\begin{array}{c}59.6 \\
(56.3-69.7)\end{array}$ & $\begin{array}{c}49.7 \\
(47.7-55.4)\end{array}$ & $\begin{array}{c}59.6 \\
(56.3-69.7)\end{array}$ & 24.1 & Yes \\
\hline Rectal-1 & 20 Gy (5) & $\begin{array}{c}27.7 \\
(21.9-30.4)\end{array}$ & $\begin{array}{c}23.1 \\
(19.2-24.8)\end{array}$ & $\begin{array}{c}28.7 \\
(26.2-30.6)\end{array}$ & 9.4 & No \\
\hline Rectal-2 & 35 Gy (7) & $\begin{array}{c}66.5 \\
(35.4-87)\end{array}$ & $\begin{array}{c}54.6 \\
(34.2-66.9)\end{array}$ & $\begin{array}{c}72.1 \\
(62.8-87.3)\end{array}$ & 46.5 & - \\
\hline Prostate-1 & 25 Gy (5) & $\begin{array}{c}39.3 \\
(33.1-41.8)\end{array}$ & $\begin{array}{c}32.8 \\
(28.8-34.3)\end{array}$ & $\begin{array}{c}40.3 \\
(39.1-41.8)\end{array}$ & 3.52 & Yes \\
\hline Prostate-2 & 36 Gy (12) & $\begin{array}{c}48.2 \\
(44-50.9)\end{array}$ & $\begin{array}{c}40.1 \\
(37.3-42)\end{array}$ & $\begin{array}{c}48.8 \\
(47-50.9)\end{array}$ & 7.872 & Yes \\
\hline Prostate-3 & 35 Gy (7) & $\begin{array}{c}52 \\
(39.5-57.1)\end{array}$ & $\begin{array}{c}43.3 \\
(35.1-46.5)\end{array}$ & $\begin{array}{c}52.5 \\
(49.5-56)\end{array}$ & 13.3 & No \\
\hline Prostate- 4 & 35 Gy (7) & $\begin{array}{c}52.1 \\
(42-56)\end{array}$ & $\begin{array}{c}43.4 \\
(36.9-45.8)\end{array}$ & $\begin{array}{c}52.6 \\
(50.3-55.6)\end{array}$ & 14.8 & No \\
\hline HCC-1 & $60 \mathrm{~Gy}(12)$ & $\begin{array}{c}67.7 \\
(42.9-83.5)\end{array}$ & $\begin{array}{c}88.2 \\
(55.9-108.9)\end{array}$ & $\begin{array}{c}114.1 \\
(85.9-142.5)\end{array}$ & 69.3 & No \\
\hline
\end{tabular}

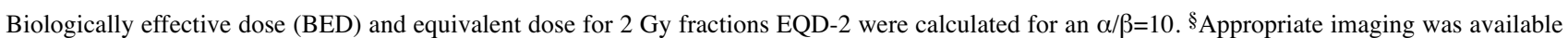
for 18 lesions. HCC: Hepatocellular carcinoma; NSCLC: non-small-cell lung cancer; SCLC small-cell lung cancer.

Doses to organs at risk $(O A R)$. Mean ipsilateral kidney dose 6.5 Gy (Mean EQD-2 $(\alpha / \beta=3)$; standard deviation $(\mathrm{SD})=5.8$ Gy). Three patients received doses above $15 \mathrm{~Gy}$ (27.7 Gy, 15.2 Gy, and 17.4 Gy; EQD-2 (for $\alpha / \beta=3$ ) was $28.5 \mathrm{~Gy}, 11$ $\mathrm{Gy}$, and $15.1 \mathrm{~Gy})$. The mean value for the maximum point dose to the small intestine in all patients was 33.1 Gy (EQD2 for $\alpha / \beta=10, \mathrm{SD}=17.9 \mathrm{~Gy}$ ).

The highest dose to the small intestine $\left(D_{5 \mathrm{~cm}^{3}}\right.$, including duodenum) was 28.9 Gy in 12 fractions [EQD-2 (for $\alpha / \beta=10$ )=31.3 Gy; EQD-2 (for $\alpha / \beta=3$ )=29.9 Gy]. Besides 
Table III. Baseline characteristics of patients with adrenal metastases.

\begin{tabular}{|c|c|}
\hline & $\begin{array}{c}\text { Number of patients } \\
\text { (lesions }{ }^{\S} \text { ) }\end{array}$ \\
\hline \multicolumn{2}{|l|}{ Primary tumor } \\
\hline \multicolumn{2}{|l|}{ Lung Cancer } \\
\hline NSCLC - Adenocarcinoma & 4 \\
\hline NSCLC - Squamous Cell & 2 \\
\hline NSCLC - Large Cell & 1 \\
\hline SCLC & $2(3)$ \\
\hline \multicolumn{2}{|l|}{ Sarcoma } \\
\hline Angiosarcoma & 1 \\
\hline Undifferentiated, pleomorphic & 1 \\
\hline Myxoid Liposarcoma & 1 \\
\hline Prostate Carcinoma & $2(4)$ \\
\hline Colorectal Adenocarcinoma & 2 \\
\hline Melanoma & $1(2)$ \\
\hline Hepatocellular carcinoma (HCC) & 1 \\
\hline Total & $18(22)$ \\
\hline \multicolumn{2}{|l|}{ Primary indication for radiotherapy* } \\
\hline Oligometastatic & 9 \\
\hline Oligoprogression & $6(9)$ \\
\hline Palliative & 2 \\
\hline Other & $1(2)$ \\
\hline \multicolumn{2}{|l|}{ Local extension } \\
\hline Adrenal gland only & $15(19)$ \\
\hline Retroperitoneal lymph nodes & 2 \\
\hline Local invasion (pancreas, kidney) & 1 \\
\hline \multicolumn{2}{|l|}{ Prior local treatment } \\
\hline None & $15(19)$ \\
\hline Recurrence after radiofrequency ablation (RFA) & 1 \\
\hline Recurrence after surgery & 1 \\
\hline Incomplete resection (R2) & 1 \\
\hline
\end{tabular}

$\S$ Number of lesions is shown if different from number of patients (both sides were treated in 4 patients). *One patient with oligometastases had weak pain symptoms. Two patients treated for palliative reasons also had oligoprogression. The patient rated as "other" was an untypical presentation of slowly progressive extensive disease SCLC who was locally treated after five lines of chemotherapy. HCC: Hepatocellular carcinoma; RFA: radiofrequency ablation; NSCLC: non-small-cell lung cancer; SCLC small-cell lung cancer.

diarrhea and fatigue (grade I), there was no significant toxicity in this patient. For individual patient doses to OAR see Table I.

Toxicity. No high-grade acute toxicity was observed. Overall, $50 \%(n=9)$ of patients reported at least one adverse event during radiotherapy. Fatigue was reported by $33 \%(n=6$, all grade I), nausea was reported by $28 \%$ of patients $(n=5$, grade II in 3 patients, grade I in 2 patients). Dyspepsia and diarrhea were reported by one patient; additionally, one patient had preexisting symptomatic diarrhea and dyspepsia which continued during radiotherapy and were not attributed to therapy. Subsequent or late toxicity events occurred intermittently in three patients and were maximal grade I in all cases (pain, dyspepsia, and nausea).

Efficacy, symptom control. Only two patients were primarily irradiated due to symptoms, one because of pain, diarrhea and nausea, the other because of pain. Symptoms resolved in one patient (pain only) and improved in the other patient (pain, diarrhea and nausea) within 30 days after radiotherapy.

Efficacy, overall survival. At the date of the last cut-off (02$2018), 44 \%(8 / 18)$ of patients were alive and $56 \%$ of patients had died (10/18). Median OS was 11.9 months (mean=17.7 months). The earliest OS event occurred in a patient with SCLC at 1.3 months, the longest survival of alive patients was 43.5 months in a patient with prostate carcinoma, see Figure 2a.

Local control. Local failures occurred in 5 out of 22 lesions $(22.7 \%)$. The median local failure-free survival was 21.6 months (mean: 18.3 months) for all evaluable lesions $(n=18)$. Treated metastases which failed were prostate (two out of four), lung (one out of nine), and melanoma (both treated lesions failed). There was no association between EQD-2 (for $\alpha / \beta 10$ ) or lesion size, measured as gross tumor volume $\left(\mathrm{GTV}, \mathrm{cm}^{3}\right)$ and local failure in our patient cohort (Table II). Out of five lesions that failed locally, three were eligible for salvage treatment after radiotherapy, two lesions were salvaged with radiofrequency ablation and one lesion in the melanoma patient was surgically resected; local recurrence was histologically confirmed in this lesion (mean EQD-2 (PTV, $\alpha / \beta=10$ ) 120 Gy). Table II shows further details on patterns of dose, volume and local failure of lesions.

Progression-free survival. Median time to any progression or death was 3.1 months (mean=9.1 months, see Figure $2 b$ ).

Details on subgroups. Patients who were treated for oligometastatic disease had the longest OS (median: 33 months) compared to oligoprogressive patients (median: 6.5 months), and palliative patients (median 1.6 months), see Figure 2c. Palliative patients included two symptomatic patients and one patient with SCLC who could not receive any further chemotherapy but opted for local treatment of multiple lesions. Oligometastatic and oligoprogressive patients had a significantly longer OS compared to other patients $(p=0.004)$; however, the informative value of this test is limited by the very small sample size (15 vs. 3 patients). The difference between oligometastatic and oligoprogressive patients was not significant $(p=0.39)$. 
a

Overall Survival

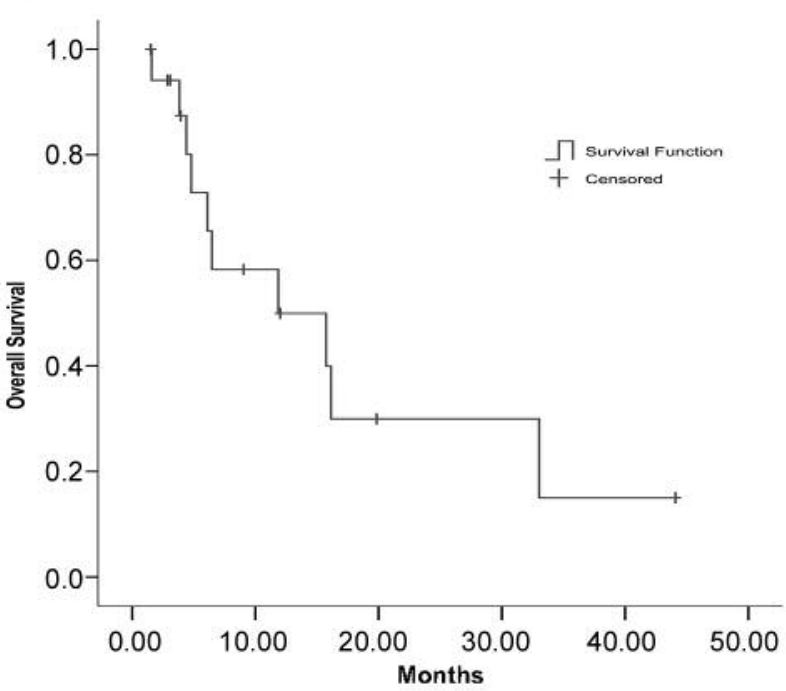

b

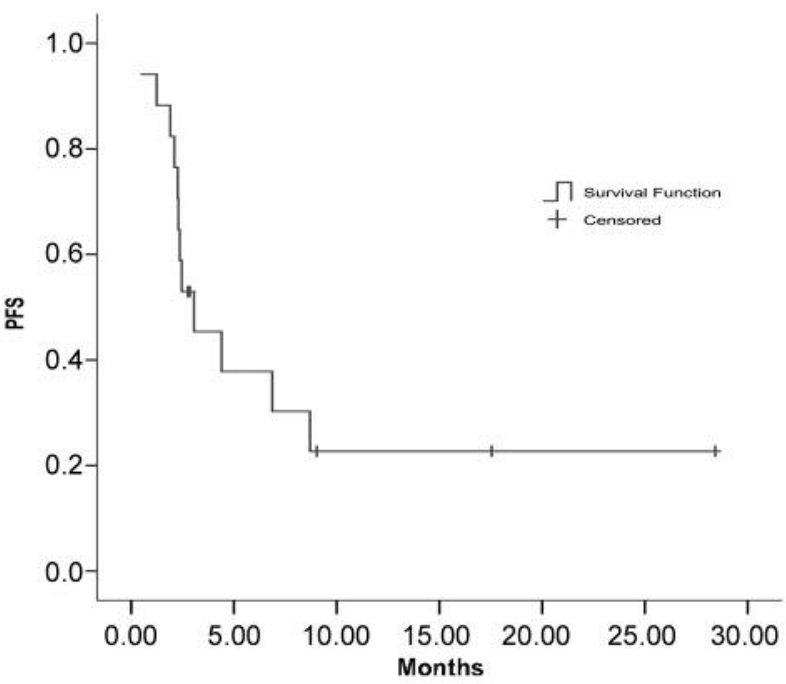

\section{Discussion}

Our retrospective analysis adds to the mounting evidence that conformal radiotherapy of adrenal lesions is safe and can be associated with long-term local control in selected patients (2, 17). Aside from palliative radiotherapy for symptomatic lesions, it is currently not established which patients benefit from stereotactic or conventional radiotherapy to the adrenal gland. Several small but well-conducted prospective studies showed a clinical benefit from radiotherapy (or surgery) to all lesions in patients with oligometastatic prostate (18), NSCLC (19-21), or breast (22) cancer. Although application of hypofractionated ablative doses was encouraged in these
C

Overall Survival

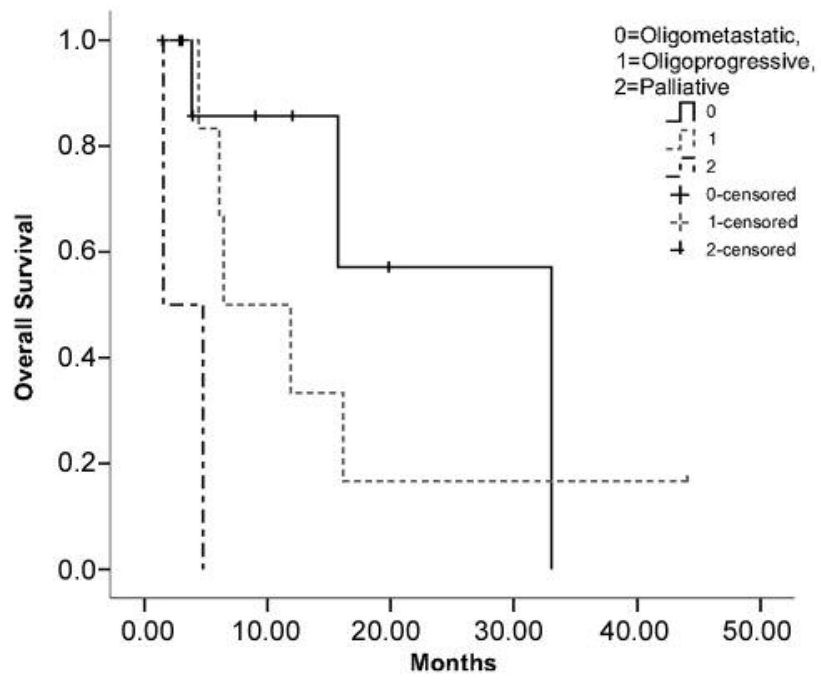

Figure 2. Survival curves. a) Overall survival function for all patients. Median OS was 11.9 months, mean survival time was 17.7 months. At the cut-off date, 10 out of 18 patients had died. b) Progression-free survival function: Median time to any PFS event was 3.1 months (mean=9.1 months). c) Comparison of overall survival curves for patients treated for oligometastatic lesions (median OS: 33 months), oligoprogression (median OS: 6.5 months) or palliative indication (median OS 1.6 months).

studies, conventional fractionation $(21,22)$ or lower doses (EQD-2 <45 Gy) $(19,20)$ were also allowed in some, and currently there is no established optimal dose or fractionation concept for certain locations or tumor types. Some patients in our study were treated due to oligoprogression, defined as a limited number of progressive metastases in a patient with an undefined number of lesions. As discussed above, the definition of oligoprogressive disease is currently debated in the literature $(6,7)$. In our cohort, oligometastatic patients had a more favorable outcome compared to oligoprogressive patients but in our small population, this observation was not statistically significant and the state of oligoprogression remains to be evaluated in further studies.

The definition of oligometastatic may vary between different histological tumor types. Prognostic models for prostate carcinoma indicate that visceral metastases are a negative prognostic factor in patients with metastatic disease (23). It has not been established if local therapy can provide a clinical benefit in this situation or if visceral metastases in prostate carcinoma are a hallmark of advanced metastatic disease in every patient. Aforementioned study by Ost et al. (18) which provides the best available (phase II) evidence for local treatment in oligometastatic prostate carcinoma, included mainly patients with bone and lymph node metastases but only one patient with a visceral lesion who did 
not receive radiotherapy but surgery (lung metastasectomy) Both prostate carcinoma patients in our series had two-sided progressive adrenal metastases with otherwise stable bone lesions. Further interpretations based on their outcome are limited since our data indicate significant heterogeneity: One patient quickly progressed and died six months after radiotherapy. The other patient was alive 43 months after radiation treatment and required salvage treatment due to two-sided local failure of the adrenal metastases.

Uncertainty also exists in SCLC: A prospective phase II trial (RTOG 0937) showed a prolonged time to progression if 1-4 metastases were irradiated in these patients; however, 1 -year OS results crossed the futility boundary and the study was closed prematurely (1-year OS $50.8 \%$ vs. $60.1 \%$ with and without consolidative radiotherapy) (24). In our series, two patients with SCLC were treated, one being classified as oligometastatic. Both patients had a short PFS ( $<3$ months). In the light of the results of RTOG 0937, definition and treatment of oligometastases in SCLC continues to be an individualized treatment decision which should be discussed in a multidisciplinary tumor conference.

Most data for the oligometastatic patients exist for NSCLC (19-21, 25, 26), our patient cohort included seven patients with NSCLC of which one with a non-ablative dose regimen failed locally after 11 months (EQD-2: 32.5 Gy), he died a few days after diagnosis of progressive disease due to tumor-associated pulmonary embolism. All other NSCLC patients remained locally controlled over a mean survival time of thirteen months.

Sarcomas have been described as radio-resistant tumors and a recent international survey showed uncertainty between institutions concerning the treatment indication for oligometastatic sarcoma $(27,28)$. Results from three patients with sarcomas in our study indicate an acceptable local control in adrenal lesions. All three patients responded to treatment without local progression over time (angiosarcoma, myxoid liposarcoma and undifferentiated pleomorphic sarcoma): Two patients had a partial remission and one patient remained in local remission after postoperative radiotherapy following incomplete surgical resection (R2).

Optimal dose-/fractionation regimens for patients with adrenal metastases have not been established. A variety of hypo- and conventionally fractionated approaches showed acceptable tumor control and very limited toxicity (17). Our study confirms that highly conformal radiotherapy can be applied with a low risk of non-serious side effects if doseconstraints are respected. Concerning symptom control in patients with pain or discomfort, our data confirm the literature: Out of two patients with relevant clinical symptoms and a sufficient follow-up, both experienced palliation of pain and discomfort, either during or after radiotherapy. Considering the good palliation, the limited toxicity and the good local control, radiotherapy of adrenal metastases should be discussed in all patients with limited metastases or symptomatic lesions.
Our retrospective analysis has several limitations: The total number of patients is small and the patient cohort is rather inhomogeneous, including one patient who had surgery before radiotherapy and two patients in whom adjacent lymph nodes needed to be included in the target volume. Lesion size ranged from $3.5 \mathrm{ml}$ up to $261 \mathrm{ml}$ and radiotherapy doses were not standardized but individualized to patient anatomy and presumed clinical benefit. Because of these limitations, survival analysis must be considered as purely exploratory. Furthermore, retrospective studies may over- or underestimate a treatment effect due to several biases and toxicity scored by physicians may underestimate the treatment impact on patientreported quality of life, thereby overestimating the overall treatment benefit (29). Finally, our analysis shows that some of our patients had very short survival periods after radiotherapy. Two patients had long-course irradiation (13 fractions) only 3-4 months before they died because of their tumor. Although these patients did not have relevant toxicity, shorter treatment courses would have been preferable.

\section{Conclusion}

Taken together, our study adds to the mounting evidence that irradiation of adrenal lesions is generally safe and welltolerated. Furthermore, there seems to be a subset of patients with oligometastatic disease which have a long LC and PFS after radiotherapy. These patients might have a benefit from longer therapy courses, if required to administer an ablative dose regimen.

\section{Conflicts of Interest}

DB reports personal fees from Siemens AG, personal fees from NB Capital Research GmbH, personal fees from NB Capital ApS, outside the submitted work. LR has nothing to disclose. FS reports personal fees and travel support from Elekta $\mathrm{AB}$, during the conduct of the study. KS has nothing to disclose. JF reports personal fees and nonfinancial support from Elekta AB, Stockholm, Sweden, outside the submitted work. FAG is a consultant and speaker for Carl Zeiss Meditec AG, NOXXON Pharma AG, Merck Serono GmbH, Roche Pharma AG, Siemens Healthcare Diagnostics GmbH. Research funds from Carl Zeiss Meditec AG, NOXXON Pharma AG and Elekta AB. Patents related with Carl Zeiss Meditec AG. Co-founder of $\mathrm{pab}^{2}$ cancer solutions. FW reports research grants and travel support from Elekta, during the conduct of the study. JBH reports teaching honoraria from Elekta AB, Stockholm, Sweden, during the conduct of the study.

\section{References}

1 Lenert JT, Barnett CC, Jr., Kudelka AP, Sellin RV, Gagel RF, Prieto VG, Skibber JM, Ross MI, Pisters PW, Curley SA, Evans DB and Lee JE: Evaluation and surgical resection of adrenal masses in patients with a history of extra-adrenal malignancy. Surgery 130(6): 1060-1067, 2001.

2 Gunjur A, Duong C, Ball D and Siva S: Surgical and ablative therapies for the management of adrenal 'oligometastases' - a systematic review. Cancer Treat Rev 40(7): 838-846, 2014. 
3 Soffen EM, Solin LJ, Rubenstein JH and Hanks GE: Palliative radiotherapy for symptomatic adrenal metastases. Cancer 65(6): 1318-1320, 1990.

4 Hellman S and Weichselbaum RR: Oligometastases. J Clin Oncol 13(1): 8-10, 1995.

5 Corbin KS, Hellman S and Weichselbaum RR: Extracranial oligometastases: A subset of metastases curable with stereotactic radiotherapy. J Clin Oncol 31(11): 1384-1390, 2013.

6 Richard PJ and Rengan R: Oligometastatic non-small-cell lung cancer: Current treatment strategies. Lung Cancer (Auckl) 7: 129-140, 2016.

7 Kelly P, Ma Z, Baidas S, Moroose R, Shah N, Dagan R, Mamounas E and Rineer J: Patterns of progression in metastatic estrogen receptor positive breast cancer: An argument for local therapy. Int J Breast Cancer 2017: 1367159, 2017.

8 Ippolito E, D'Angelillo RM, Fiore M, Molfese E, Trodella L and Ramella S: Sbrt: A viable option for treating adrenal gland metastases. Rep Pract Oncol Radiother 20(6): 484-490, 2015.

9 Rudra S, Malik R, Ranck MC, Farrey K, Golden DW, Hasselle MD, Weichselbaum RR and Salama JK: Stereotactic body radiation therapy for curative treatment of adrenal metastases. Technol Cancer Res Treat 12(3): 217-224, 2013.

10 Holy R, Piroth M, Pinkawa M and Eble MJ: Stereotactic body radiation therapy (sbrt) for treatment of adrenal gland metastases from non-small cell lung cancer. Strahlenther Onkol 187(4): 245-251, 2011.

11 Sarela AI, Murphy I, Coit DG and Conlon KC: Metastasis to the adrenal gland: The emerging role of laparoscopic surgery. Ann Surg Oncol 10(10): 1191-1196, 2003.

12 National Cancer Institute: Common terminology criteria for adverse events v4.0. NIH publication 09-7473, 2009.

13 Boda-Heggemann J, Knopf AC, Simeonova-Chergou A, Wertz H, Stieler F, Jahnke A, Jahnke L, Fleckenstein J, Vogel L, Arns A, Blessing M, Wenz F and Lohr F: Deep inspiration breath hold-based radiation therapy: A clinical review. Int J Radiat Oncol Biol Phys 94(3): 478-492, 2016.

14 Boda-Heggemann J, Jahnke A, Jahnke L, Simeonova A, Mai S, Wertz H, Zimmermann S, von Swietochowski F, Wenz F and Lohr F: Breath-hold cone beam ct (cbct): Improved image quality with "stop-and-go" breath hold-only acquisition versus repetitive breath hold during continuous rotation. Int J Radiat Oncol Biol Phys 90(1): Supplement, S826, 2014.

15 The International Commission on Radiation Units and Measurements: Report 91. J ICRU 14(2): 1-160, 2014.

16 R_Core_Team: R: A language and environment for statistical computing: $\mathrm{R}$ foundation for Statistical Computing, Vienna, Austria, 2015.

17 Milgrom SA and Goodman KA: The role of radiation therapy in the management of adrenal carcinoma and adrenal metastases. $J$ Surg Oncol 106(5): 647-650, 2012.

18 Ost P, Reynders D, Decaestecker K, Fonteyne V, Lumen N, De Bruycker A, Lambert B, Delrue L, Bultijnck R, Claeys T, Goetghebeur E, Villeirs G, De Man K, Ameye F, Billiet I, Joniau S, Vanhaverbeke F and De Meerleer G: Surveillance or metastasis-directed therapy for oligometastatic prostate cancer recurrence: A prospective, randomized, multicenter phase II trial. J Clin Oncol 36(5): 446-453, 2017.

19 Iyengar P, Kavanagh BD, Wardak Z, Smith I, Ahn C, Gerber DE, Dowell J, Hughes R, Abdulrahman R, Camidge DR, Gaspar LE, Doebele RC, Bunn PA, Choy H and Timmerman R: Phase ii trial of stereotactic body radiation therapy combined with erlotinib for patients with limited but progressive metastatic non-smallcell lung cancer. J Clin Oncol 32(34): 3824-3830, 2014.

20 Gomez DR, Blumenschein GR Jr., Lee JJ, Hernandez M, Ye R, Camidge DR, Doebele RC, Skoulidis F, Gaspar LE, Gibbons DL, Karam JA, Kavanagh BD, Tang C, Komaki R, Louie AV, Palma DA, Tsao AS, Sepesi B, William WN, Zhang J, Shi Q, Wang XS, Swisher SG and Heymach JV: Local consolidative therapy versus maintenance therapy or observation for patients with oligometastatic non-small-cell lung cancer without progression after first-line systemic therapy: A multicentre, randomised, controlled, phase 2 study. Lancet Oncol 17(12): 1672-1682, 2016.

21 Iyengar P, Wardak Z, Gerber DE, Tumati V, Ahn C, Hughes RS, Dowell JE, Cheedella N, Nedzi L, Westover KD, Pulipparacharuvil $\mathrm{S}$, Choy $\mathrm{H}$ and Timmerman RD: Consolidative radiotherapy for limited metastatic non-small-cell lung cancer: A phase 2 randomized clinical trial. JAMA Oncol 4(1): e173501, 2018.

22 Trovo M, Furlan C, Polesel J, Fiorica F, Arcangeli S, Giaj-Levra N, Alongi F, Del Conte A, Militello L, Muraro E, Martorelli D, Spazzapan S and Berretta M: Radical radiation therapy for oligometastatic breast cancer: Results of a prospective phase II trial. Radiother Oncol 126(1): 177-180, 2018.

23 Halabi S, Lin CY, Kelly WK, Fizazi KS, Moul JW, Kaplan EB, Morris MJ and Small EJ: Updated prognostic model for predicting overall survival in first-line chemotherapy for patients with metastatic castration-resistant prostate cancer. J Clin Oncol 32(7): 671-677, 2014.

24 Gore EM, Hu C, Sun AY, Grimm DF, Ramalingam SS, Dunlap NE, Higgins KA, Werner-Wasik M, Allen AM, Iyengar P, Videtic GMM, Hales RK, McGarry RC, Urbanic JJ, Pu AT, Johnstone CA, Stieber VW, Paulus R and Bradley JD: Randomized phase II study comparing prophylactic cranial irradiation alone to prophylactic cranial irradiation and consolidative extracranial irradiation for extensive-disease small cell lung cancer (ed sclc): Nrg oncology rtog 0937. J Thorac Oncol 12(10): 1561-1570, 2017.

25 Celik E, Semrau R, Baues C, Trommer-Nestler M, Baus W and Marnitz S: Robot-assisted extracranial stereotactic radiotherapy of adrenal metastases in oligometastatic non-small cell lung cancer. Anticancer Res 37(9): 5285-5291, 2017.

26 Janssen S, Kasmann L, Rudat V and Rades D: Stereotactic body radiation therapy (sbrt) for recurrent non-small cell lung cancer (nsclc). Anticancer Res 36(2): 825-828, 2016.

27 Tepper JE and Suit HD: The role of radiation therapy in the treatment of sarcoma of soft tissue. Cancer Invest 3(6): 587-592, 1985.

28 Dagan R, Lo SS, Redmond KJ, Poon I, Foote MC, Lohr F, Ricardi U and Sahgal A: A multi-national report on stereotactic body radiotherapy for oligometastases: Patient selection and follow-up. Acta Oncol 55(5): 633-637, 2016.

29 Laugsand EA, Sprangers MA, Bjordal K, Skorpen F, Kaasa S and Klepstad P: Health care providers underestimate symptom intensities of cancer patients: A multicenter european study. Health Qual Life Outcomes 8: 104, 2010.

Received June 12, 2018

Revised June 26, 2018

Accepted July 2, 2018 